\title{
Metastatik hastalarda tanısal algoritmalar
}

\section{Diagnostic algorithms in metastatic patients}

\author{
Melih Civan ${ }^{1}$, Levent Eralp² \\ 'Sağlık Bilimleri Üniversitesi, Gaziosmanpaşa Taksim EAH, Ortopedi ve Travmatoloji Kliniği, İstanbul \\ ${ }^{2}$ İstanbul Üniversitesi, İstanbul Tıp Fakültesi, Ortopedi ve Travmatoloji Anabilim Dalı (emekli), İstanbul
}

\begin{abstract}
İskelet sistemi, kanser hücrelerinin akciğer ve karaciğerden sonra en sık metastaz yaptığı bölgedir. Geçmişte sıklıkla palyatif tedavi yöntemlerinin tercih edildiği ve öncelikle ağrı kontrolünün amaçlandığı iskelet metastazlarının tedavi yaklaşımlarında, son yıllarda kayda değer gelişmeler yaşanmaktadır. Takip protokollerinde modern tanısal araçların rutin yer edinmesi sayesinde metastazlar daha erken tespit edilebilmektedir. Ayrica, yeni kemoterapi ve radyoterapi rejimleri, bisfosfonat ve denosumab gibi hedefe yönelik ajanların kullanımları, iskelet sistemi ile ilgili paraneoplastik hadiselerin de görülme sıklığını azaltmıştır. Bu gelişmelere ek olarak, cerrahi teknik seçenekleri de yıllar içinde zenginleşmiştir. Gerektiği zaman, osteosentez günümüzde daha minimal invaziv yöntemlerle ve düşük morbidite ile uygulanabilmekte veya geniş rezeksiyonlar sonrası başarılı rekonstrüksiyon seçenekleri ile kabul edilir fonksiyonel sonuçlar elde edilebilmektedir. Sonuç olarak; patolojik kırık, medulla spinalis basısı, hiperkalsemi gibi iskelet sistemi ile ilişkili hadiselerin sık görüldügüu, çoklu metastazlı olgularda dahi, hayatta kalım süreleri artmıştır. Biz inanıyoruz ki, ortopedik cerrahları metastaz ilişkili senaryolar ile daha sık karşı karşıya getiren bu durumdur. Ortopedik onkolojide halen birincil tümör cerrahisi daha çok alanında eğitimli ya da konuya eğilimli kişiler tarafından uygulanmakta iken, iskelet metastazları ya da patolojik kırıklar daha çok genel ortopedi ve travmatoloji uzmanları tarafindan yönetilmektedir. Bu nedenle mevcut derlemede, günlük ortopedi pratiğine de katkıda bulunacağına inanarak, onkolojide iskelet metastazlarına yaklaşımda tanısal algoritmalar anlatılacaktır.
\end{abstract}

Anahtar sözcülkler: iskelet metastazı; kemik metastazı; tanısal algoritma

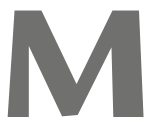
etastaz, kanserli dokularda hücreleri bir arada tutan mekanizmanın bozulmasını takiben, sırası ile hücresel göç, anjiyogenez, sistemik dolaşıma katılma, sistemik dolaşımda hayatta kalma ve lokal yanıtların atlatılmasının ardından, hedef organda büyüme ile tanımlanan neoplastik bir oluşumdur. ${ }^{[1-2]}$ Kemiğin en sık görülen malign lezyonu metastazdır. ${ }^{[3]}$ Kanserin akciğer ve karaciğer
The bone is the most common tissue for metastatic disease following lung and liver. In most of the cases, palliative treatments and pain control were primary objectives in the past. Recently, significant improvements for the treatment of metastatic disease have been achieved. Today skeletal metastases are being diagnosed earlier due to the follow-up protocols with modern diagnostic tools. Besides, the frequency of the skeletal-related events diminished as a consequence of new chemotherapy and radiotherapy protocols, and target specific agents such as bisphosphonates and denosumab. All of these improvements were followed by expanded surgical techniques. Nowadays, minimally invasive osteosynthesis resulted with lower morbidity rates; new reconstructive surgeries result in acceptable functional outcomes even after broad surgical resections. In the end, even metastatic cases complicated with skeletal-related events such as pathological fractures, spinal cord compression or hypercalcemia are related to longer survival rates. We believe that is the reason orthopedic surgeons encounter these scenarios more often. In the field of oncology, primary tumor surgeries are still performed by specialized surgeons. However, metastatic disease or pathologic fractures are mostly managed by general orthopedic surgeons. For this reason, the subject of this review is the diagnostic algorithms of skeletal metastases, by hoping of contributing the daily orthopaedic practice.

Key words: skeletal metastases; bone metastases, diagnostic algorithm

dokularından sonra üçüncü en sık metastaz yaptığı bölge iskelet sistemidir. ${ }^{[3]}$ iskelet metastazlarının ise büyük bir kısmı, "osteotropik neoplaziler" olarak da adlandırılan, meme ve prostat kanseri kökenlidir (\%70). ${ }^{[3]} \mathrm{Bu}$ durum, meme ve prostat kanserindeki göreceli uzun yaşam süreleri ya da bu malignitelerin görülme sıklığının daha fazla olması ile ilişkilendirilebilir. ${ }^{[4]}$

- İletişim adresi: Op. Dr. Melih Civan, Sağlık Bilimleri Üniversitesi, Gaziosmanpaşa Taksim EAH, Ortopedi ve Travmatoloji Kliniği, İstanbul Tel: 0505 - 8200201 e-posta: melihcivan@gmail.com

- Geliș tarihi: 12 Eylül 2019 Kabul tarihi: 22 Ekim 2019 
İskelet metastazı olan hastalarda yaşam kalitesinin artırılması ve komorbiditelerin önüne geçilebilmesi için, ağrı kontrolü, mevcut patolojik kırıkların önlenmesi ya da tedavi edilmesi hedeflenir. Bu amaçla önceleri palyatif tedavi yöntemleri tercih edilmekte iken, yıllar içinde tedavi yaklaşımlarında kayda değer gelişmeler yaşanmıştır. Pozitron emisyon tomografi (PET) taraması ve bilgisayarlı tomografi (BT) bileşimi (PET$\mathrm{BT}$ ) ya da manyetik rezonans (MR) görüntüleme gibi modern tanısal araçların takip protokollerinde yaygın olarak kullanılması ile, metastazlar daha erken tespit edilebilmektedir. Yeni kemoterapi ve radyoterapi protokolleri, bisfosfonat ve denosumab gibi hedefe yönelik ajanların kullanımları, onkolojide iskelet sistemi ile ilgili paraneoplastik sendromların ve komplikasyonların (Skeletal Related Events -SRE) görülme sıklığının azalmasını sağlamıştır. Seçili olgularda izole kemik metastazlarının küratif tedavisi amacı ile de cerrahi girişimler hedeflenmektedir. Bütün bu gelişmelere rağmen, metastazların ortalama sıklığı halen bilinmemektedir. ${ }^{[3]}$

Kanser hastalarında iskelet morbiditesini, kemiğin metastaz yükü ve kanser tedavisinin indüklediği kemik kaybı belirler. Bu nedenle, ortopedik onkolojide cerrahi teknik seçeneklerinin yıllar içinde zenginleşmesi, iskelet metastazlarının yönetiminde önemli avantajları beraberinde getirmiştir. Osteosentez, günümüzde sıkIıkla minimal invaziv tekniklerle uygulanabilmekte ya da geniş rezeksiyonlara rağmen başarılı rekonstrüksiyon seçenekleri ile morbiditede kayda değer azalmalara olanak sağlanmaktadır. Dolayısıyla, kırık, medulla spinalis basısı, hiperkalsemi gibi SRE'lerin sık görüldügü, çoklu (multiple) metastazlı olgularda dahi artan hayatta kalım süreleri, ortopedik cerrahların metastaz ilişkili senaryolar ile daha sık karşı karşıya gelmesi ile sonuçlanmaktadır.

\section{KEMIK METASTAZLARINDA TANISAL ARAÇLAR}

Kemik metastazları, ağrı, hareket yeteneğinde azalma, patolojik kırıklar, medulla spinalis basısı, kemik iliği aplazisi ve hiperkalsemi ile karakterize morbiditelere, diğer bir tanımlama ile SRE'lere neden olur. Olguların yarısından fazlasında femur tutulumu olmak üzere, çoğunlukla uzun kemiklerin proksimal kısmında görülen patolojik kırıkların kanser hastalarında görülme sıklığı \%10 ile \%30 arasındadır. ${ }^{[5]}$ Sürekli statik kuvvetlere maruz kalan pelvis, femur ya da vertebral kolon gibi yapılar metastaz sonucu erken dönemde semptomatik olabilirken, kafatası ve kosta gibi yük altında olmayan kemikler çok geç dönemde semptomatik hale gelir. ${ }^{[6,7]}$ Hareket esnasında ağrı, sıklıkla, meydana gelebilecek bir uzun kemik kırığının erken habercisidir.
Kanser hastalarında görülen ağrıların karakteristik özelliği; zor lokalize edilen, geceleri kötüleşen, uyku ya da dinlenmek ile rahatlamayan ve inflamatuvar ya da mekanik karakterde olabilen kemik ağrısı olarak tanımlanabilir. Bu ve bunun gibi iskelet metastazı düşündüren semptomlar ile başvuran hastalarda, görüntüleme yöntemlerinden önce, anemi ya da kemik iliği baskılamasının tespit edilmesi ve kemik yapım-yıkım döngüsü (turnover) ile hiperkalseminin tanımlanması amacı ile de tam kan sayımı, serum kalsiyum, fosfor, $25-(\mathrm{OH})$ vitamin D, alkalen fosfataz, kreatinin, tiroid stimülan hormon, protein elektroforezi, paratiroid hormon seviyeleri gibi yardımcı laboratuvar parametrelerine bakılması esastır. Ağrı ve patolojik kırık dışında hiperkalsemi, ileri evre kanser hastaları için yaygın bir patolojidir. Metastatik hastaların \%10'unda metastaz ile ilişkili hiperkalsemi görülmekte iken, olguların büyük bir kısmında, paratiroid hormon ilişkili peptid (PTHrP) ile ilişkili paraneoplastik sendrom sonucu hiperkalsemi görülür. ${ }^{[8]}$ Bu laboratuvar tetkiklerinin ardından, görüntüleme yöntemlerinin kullanılması gerekir.

Düz radyografiler, kemik metastazlarının tespit edilmesinde ucuz, hızlı ve pratik görüntüleme yöntemleridir. Kanserli hastada iskelet metastazlarının radyografik incelemesi düz grafi ile başlamalıdır. Düz grafi ile, hem lezyonun lokalizasyonu hem de komşu eklem bölgeleriyle ilişkisi değerlendirilir. Düz grafinin iskelet metastazlarında özgüllüğü yüksek olmasına rağmen duyarlılığı düşüktür (\%44-50). ${ }^{[9]}$ Düz grafi ile, özellikle bir santimetrenin altındaki lezyonlar gözden kaçabilir. Ayrıca, bir metastazın düz grafide tespit edilebilmesi için kortikal kemiğin \%50'sinden fazlasında yıkım meydana gelmiş olması, $1 \mathrm{~cm}$ çapından daha büyük olması ve kemik mineral yoğunluğunda en az \%25-50 azalma olması gerekir. ${ }^{[10]}$ Düz grafide medüller lezyonlar kortikal lezyonlara göre daha zor tespit edilir. Meme kanserinde prototip lezyon olarak tanımlanan osteolitik kemik metastazları, gri-beyaz tonlu kemik görüntüsü üzerinde radyolüsen siyah oluşumlar olarak görülürken, prostat kanserinin tipik osteoblastik metastazları ise normal tonundan daha beyaz noktalar olarak görüntülenir. ${ }^{[11]}$

Metastatik lezyonların tespit edilmesinde BT'nin duyarlılığı ise \%71 ile \%100 arasında değişmektedir. Kemik yıkımı (osteolitik) ve sklerotik lezyonlar ya da artıklar kolaylıkla tespit edilebilirken, kemik metastazlarının yumuşak doku uzanımları da görüntülenebilir. BT'nin bu özellikleri, aynı zamanda başarı ile biyopsi planlanmasında kullanılmasını yaygınlaştırmıştır. ${ }^{[12]}$

MR görüntülemenin iskelet metastazlarında temel kullanım alanı, medulla spinalis basısının ve kemiğin medüller bölgesindeki lezyonların araştırılmasıdır. 
Yöntemin duyarlılı̆̆ \%82 ile \%100 arasında değişkenlik gösterirken, özgüllük \%73-100'dür .[13] Bu avantajları nedeni ile, ameliyat öncesi ve radyoterapi planlamasında yaygın olarak MR kullanılmaktadır.

Technetium-99 ( ${ }^{99 \mathrm{~m} T c)}$ sintigrafisi, kanserin birincil evrelemesinde, takip muayenelerinde, kür sonrası rutin taramalarda yaygın olarak kullanılan, göreceli olarak pahalı olmayan ve tüm vücudu tarayabilen bir yöntemdir. İskelet sisteminde kullanım alanı neoplazi ile sınırlı olmayan sintigrafi, kemiğin vaskülaritesi ve osteoblastik aktivitesi hakkında bilgi verir. ${ }^{99 \mathrm{~m}} \mathrm{Tc}$ sintigrafisinin iskelet metastazlarının görüntülenmesinde $\% 62-89$ duyarlılığı ve $\% 40$ 'a varan oranda yalancı pozitifliği bildirilmiştir. ${ }^{[14]}$ Ancak, yine de düz röntgenogramlardan ve BT'den daha duyarlı ve özgündür. Vertebral metastazlarda ise $M R$, sintigrafiye daha üstündür. ${ }^{[15]} \quad 99 \mathrm{~m} T c$-metildifosfonat (MDP) kemik sintigrafisi, iskelet metastazlarının tespit edilmesinde en yaygın kullanılan radyonüklid yöntemdir. ${ }^{99 \mathrm{~m} T c-M D P}$, metastazları radyografiden aylar önce görüntüleyebilir; tüm vücudun taranmasına olanak sağlar, teknik olarak ulaşılabilir, maliyet etkin ve yüksek duyarlılığa sahiptir. Yöntemin tespit yeteneği kemik oluşum mekanizması ile ilişkili olduğu için, özellikle osteoblastik ya da karma (litik-blastik) karakterdeki meme ve prostat kanseri metastazlarında çok yararlıdır. ${ }^{[16]}$ Ancak diğer yönden, reaktif kemik oluşumu içermeyen küçük boyutlu metastazların, intramedüller metastazların ya da saf litik lezyonların tespitinde kullanım alanı kısıtıdır. Osteoblastik karakterli artroz, inflamasyon ve travma gibi iyi huylu patolojilerde karşılaşılan yanlış-pozitif sonuçlardan ötürü, yöntemin özgüllüğü düşüktür.

PET, metabolik aktivite tespiti ilkesine dayanarak, tümörü direkt görüntülemede kullanılır. Özellikle akciğer (duyarlılık \%92, özgüllük \%99) ve meme (duyarlılık \%92, özgüllük \%99) kanserlerinde, kemik sintigrafisine göre üstündür. ${ }^{[17,18]}$ Böbrek ve prostat kanseri kemik metastazlarındaki düşük metabolik aktivite nedeni ile, tanısal isabet oranı daha düşüktür. ${ }^{[19]}$ Son yıllarda PET teknolojisindeki ilerlemelere paralel olarak, yeni radyofarmasötik ajanların kullanımları ile daha yüksek tanısal isabet oranlarına, daha yüksek çözünürlüklere, daha kısa görüntüleme zamanlarına ulaşılmış ve yumuşak doku lokal rekürrensleri ile metastazların aynı görüntülemelerde tespit edilmesi avantajlarına kavuşulmuştur (Tablo 1). Bu avantajlara rağmen, bu ajanlar iskelet metastazlarına \%100 özgül değildir. İyi huylu ya da neoplastik olmayan kemik patolojilerinin yanı sıra osteoliz ve osteoskleroz gibi BT'deki morfolojik değişikliklerin de göz önünde bulundurulması ile daha doğru sonuçlara ulaşılması mümkündür. Solid tümörlerde tedavi yanıtlarının değerlendirilmesinde kullanılan görüntüleme yöntemleri arasında PET-BT ilk sırada yer almaktadır (Tablo 2, Şekil 1). ${ }^{[20]}$
İskelet metastazlarında, biyopsiler tanısal algoritmalarda yer tutan önemli araçlardır. İnce iğne aspirasyon biyopsisi, çekirdek-iğne biyopsisi ya da açık biyopsi şeklinde yapılabildiği gibi BT ya da MR görüntüleme kılavuzluğunda da yapılabilir. Son yıllarda kullanım alanı bulan genetik temelli ve özel adlandırıması ile "sıvı biyopsiler" kemik iliği ve serumun analizine dayanmaktadır. Kanser hücrelerindeki tümöre özgü mutasyonlar genom, $\mathrm{m}$-RNA veya protezin sentezi temelli tespit edilmeye çalışılarak, metastazların davranış paternleri hakkında öncül bilgiler elde edilebilmektedir (Tablo 3). ${ }^{[9]}$

\section{UZUN KEMIK METASTAZLARI TANISAL ALGORITMALARI}

Kanser hastalarında iskelet metastazlarının yönetiminde geçmişten günümüze benzer birçok tanısal algoritma yayımlanmıştır. ${ }^{[31-37]}$ Ortopedist ve onkologlara en uygun tedaviyi sunmak amacı ile geliştirilen bu algoritmaların, multidisipliner yaklaşım ile ele alınması ve uygulanması hastaların yararına olacaktır. Kanser hastalarında, spinal instabilite veya patolojik kırık riski taşımayan metastazlar için yalnızca gözlem önerilmektedir. Tedavi ise hastanın genel klinik durumu, ortalama yaşam beklentisi ve kalitesi gibi değişkenlere göre farklılıklar gösterir. Uzun kemik metastazlarına yaklaşımda kullanılan klasik bir algoritma Şekil 2'de gösterilmiştir. ${ }^{[38]}$

Agresif bir kemik lezyonunda, primeri bilinen onkolojik hastada ilk cevaplanması gereken soru, kemik lezyonlarının (metastazların) sayısıdır. ${ }^{[34-35]}$ Lezyonun soliter olduğundan emin olunduğunda, tümör ile iliş̧kili prognostik faktörler incelenmeli ve düz radyografiden PET-BT'ye kadar çok sayıda görüntüleme yöntemleri yardımı ile evreleme yapılmalıdır. Meme kanseri öyküsü olan bir hastada, izole soliter bir kemik lezyonu tespit edildiğinde, en muhtemel tanı iskelet metastazı olmakla birlikte; multipl miyelom, primer kemik tümörü, lenfoma, enfeksiyon, Paget hastalığı ve hiperparatiroidizm ayırıcı tanıda yer alır. Bu durumda biyopsi yalnızca, tümör benzeri lezyonlarda, ayırıcı tanı gerektiğinde ya da ablatif cerrahi planlandığında uygulanır. Laboratuvar bulguları, hastanın medikal durumu ve tümörün lokal evrelemesi, yapılacak cerrahinin (radikal ya da palyatif) amacını belirler.

Çoklu kemik metastazı durumunda cerrahi her zaman palyatif amaçla yapılır. Bu durumda, kemiğin etkilenme derecesinin hastanın durumundan bağımsız olarak değerlendirilmesi gerekir. Kırık riskinin öngörülebilmesi amacı ile, soliter metastazlarda Mirels'in skorlama sistemi kullanılır. ${ }^{\left[{ }^{[6]}\right.}$ Bu skorlama sistemine göre 9 puan ve üzerindeki lezyonlarda 
Tablo 1. İskelet metastazlarının tanısal algoritmalarında radyofarmasötik PET ajanları

\section{Radyofarmasötik ajan Özellikleri}

${ }^{18}$ F-Floride $\left({ }^{18} \mathrm{~F}-\mathrm{NaF}\right)$

Bu ajan 99mTc-MDP'nin kullanımından çok önce, 1962'de klinik kullanıma girmiş, FDA onayı ise 1972 yılında alınmıştır. Bir dönem popülaritesindeki azalmaya rağmen günümüzde PET-BT görüntüleme nedeni ile yeniden ilgi odağı olmuştur. Shen ve ark.'nın 20 makale ve 1170 hastanın dâhil olduğu meta-analizinde, ${ }^{18} \mathrm{~F}-\mathrm{NaF}$-PET ya da

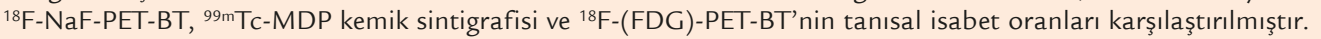
99mTc-MDP ile karşılaştırıldığında, ${ }^{18} \mathrm{~F}-\mathrm{NaF}-\mathrm{PET}$ ya da ${ }^{18} \mathrm{~F}-\mathrm{NaF}$-PET-BT’nin daha yüksek duyarlılık ve özgüllüğe sahip olduğu gösterilmiştir. ${ }^{18} \mathrm{~F}$-(FDG)-PET-BT ile karşılaştırıldı ğında, ${ }^{18} \mathrm{~F}-\mathrm{NaF}$-PET ya da ${ }^{18} \mathrm{~F}-\mathrm{NaF}-\mathrm{PET}$-BT'nin daha yüksek duyarlılık ancak benzer özgüllük oranlarına sahip olduğu gösterilmiştir. ${ }^{[21]}{ }^{18} \mathrm{~F}-\mathrm{NaF}$-PET-BT günümüzde \%94 tanısal isabet oranına sahiptir. ${ }^{[22]}$ Sampath ve ark.'nın yaptığı çalışmada, yumuşak doku metastazlarında FDG, kemik metastazlarında ise NaF ile kombine edilen PET-BT, metastatik hastalığın tespit edilmesinde tüm vücut MR, BT ve ${ }^{99 m}$ Tc-MDP sintigrafisi ile kombine taramalara belirgin üstün olarak saptanmış ve bu amaçla kullanılan en iyi yöntem olarak tanımlanmıştır. ${ }^{[23]}$ Bütün bu üstün özelliklerine rağmen inflamatuvar artrit, osteomiyelit, kırık, fibröz displazi, kemiğin Paget hastalığı gibi birçok neoplastik olmayan patolojide, değişken yoğunlukta ${ }^{18} \mathrm{~F}-\mathrm{NaF}$ tutulumu gözlemlenmektedir. Özellikle osteolitik lezyonların tespitinde kullanılan bu ajanın, yüksek radyasyon dozları ve yüksek maliyeti dezavantajlarıdır. ${ }^{[24]}$

${ }^{18}$ F-Flurodeoxyglucose $\left({ }^{18} \mathrm{~F}-\mathrm{FDG}\right)$

${ }^{18}$ F-Fluciclovine

${ }^{11}$ C-Choline
FDG, içerisinde glikoz barındıran ve daha çok neoplastik patolojilerin tespit edilmesinde kullanılan bir ajandır. Konvansiyonel görüntülemelerden önce kemik formasyonundaki değişimlerin FDG ile tespit edilmesi mümkündür. Tedavi edilmemiş litik lezyonlarda FDG tutulumu, sklerotik lezyonlardan daha yüksektir. Bazı çalışmalar, meme kanseri metastazlarının tespit edilmesinde, tek başında sintigrafiye oranla FDG-PET-BT’nin daha yüksek duyarlılık ve özgüllüğe sahip olduğunu savunmaktadır. ${ }^{[25,26]}$ Bazı merkezlerde, FDG-PET prostat kanserinin yumuşak doku metastazlarının tespit edilmesinde tercih edilmektedir. FDG, nöroendokrin komponenti olan tümörlerin metastaz tespitinde diğer ajanlardan daha başarılıdır. ${ }^{[27]}$ Bu nedenle, FDG-PET-BT küçük hücreli ve küçük hücreli olmayan akciğer kanserlerinin litik kemik metastazlarının tespitinde, papiller RCC hastalarında nefrektomi sonrası ve tiroid kanserlerinin kemik metastazlarında başarı ile kullanılmaktadır.

Bu ajan artmış PSA seviyeleri olan prostat kanseri rekürrensinde ve prostat, meme ve gliom neoplazilerinin tanısında kullanılmaktadır. Bu molekülü diğerlerinden ayıran özelliği, düşük makrofaj tutulumu nedeni ile inflamatuvar hastalıklardaki yanlış pozitiflik oranlarının düşük olmasıdır. Ne yazık ki bu ajanın kemik metastazlarının tespit edilmesindeki başarısı ile ilgili fazla sayıda çalışma yapılmamıştır. Nanni ve ark.'nın yaptığı bir çalışmada, ${ }^{18} \mathrm{~F}$-Fluciclovine’in ${ }^{11} \mathrm{C}$-Choline'e oranla lokal, lenf nodu ve iskelet metastazlarını tespit etmede daha başarılı olduğu görülmüştür. ${ }^{[28]}$ Schuster ve ark., negatif tüm vücut taramasına sahip 93 hastanın üçünde ${ }^{18} \mathrm{~F}$-Fluciclovine ile kemik metastazı tespit etmişlerdir. [28] ${ }^{18}$ F-Fluciclovine ile litik lezyonlarda yoğun bir tutulum gözlenirken, karma litik/sklerotik lezyonlarda orta derecede bir tutulum gözlemlenir. Ancak, çok yoğun litik lezyonlarda hiç tutulum tespit edilemeyen olgular da mevcuttur. Bu ajan ile ilgili mevcut literatürdeki çalışmalar hâlâ yeterli sayıda değildir ve prostat kanser taramasında ${ }^{18}$ F-Floride PET-BT halen bu moleküle üstün olarak görülmektedir. ${ }^{[14]}$

Bu ajan, biyokimyasal olarak tespit edilen prostat kanserinin rekürrensinde kullanılma amacı ile 2012 yılında FDA onayı almıştır. Kolinin tümör hücrelerinde fosforile koline dönüşerek tutsak edilmesi ile 20 dakikalık yarı ömrü içinde görüntüleme vermektedir. Prostat kanserinde kemik üretimi rezorpsiyondan sonra meydana geldiği için, osteolitik, osteoblastik ve intramedüller metastazlara rastlanabilmektedir. ${ }^{[29]}$ Geleneksel olarak prostat kanserinin osteoblastik eğilimli kemik metastazlarının tespit edilmesinde sintigrafi ve BT kullanılır. Ancak, bazı çalışmalarda ${ }^{11} \mathrm{C}$-Choline-PET-BT'nin diğer sintigrafilerden daha üstün olduğu öne sürülmektedir. ${ }^{\left[{ }^{30]}\right.}$ Ayrıca ${ }^{11} \mathrm{C}$-Choline-PET-BT sklerotik olmayan ve BT'de görülmeyen metastazları saptayabilme yeteneği kemik taramaya (bone scan) üstündür. ${ }^{[29]}$

FDA, US Food and Drug Administration; PET, pozitron emisyon tomografi; MDP, metildifosfonat; BT, bilgisayarlı tomografi; FDG, florodeoksiglukoz; PSA, prostata özgü antijen; RCC, böbrek hücreli karsinom.

Tablo 2. RECIST kriterlerine göre solid tümörlerde tedavi yanıtının değerlendirilmesinde kullanılan görüntüleme yöntemleri[20]

\begin{tabular}{lcc}
\hline Görüntüleme/araştırma yöntemi & Duyarlılık (sensitivite) \% & Özgüllük (spesifisite) \% \\
\hline${ }^{18}$ F-NaF-PET-BT & 100 & 97 \\
MR görüntüleme & 95 & 90 \\
SPECT & 87 & 91 \\
${ }^{18}$ F-(FDG)-PET-BT & 98 & 56 \\
BT & 74 & 56 \\
Kemik sintigrafisi & 78 & 48 \\
\hline
\end{tabular}

RECIST, solid tümörlerde cevap değerlendirme kriterleri; PET, pozitron emisyon tomografi; BT, bilgisayarlı tomografi; MR, manyetik rezonans; SPECT, tek foton emisyon bilgisayarlı tomografi; FDG, florodeoksiglukoz. 


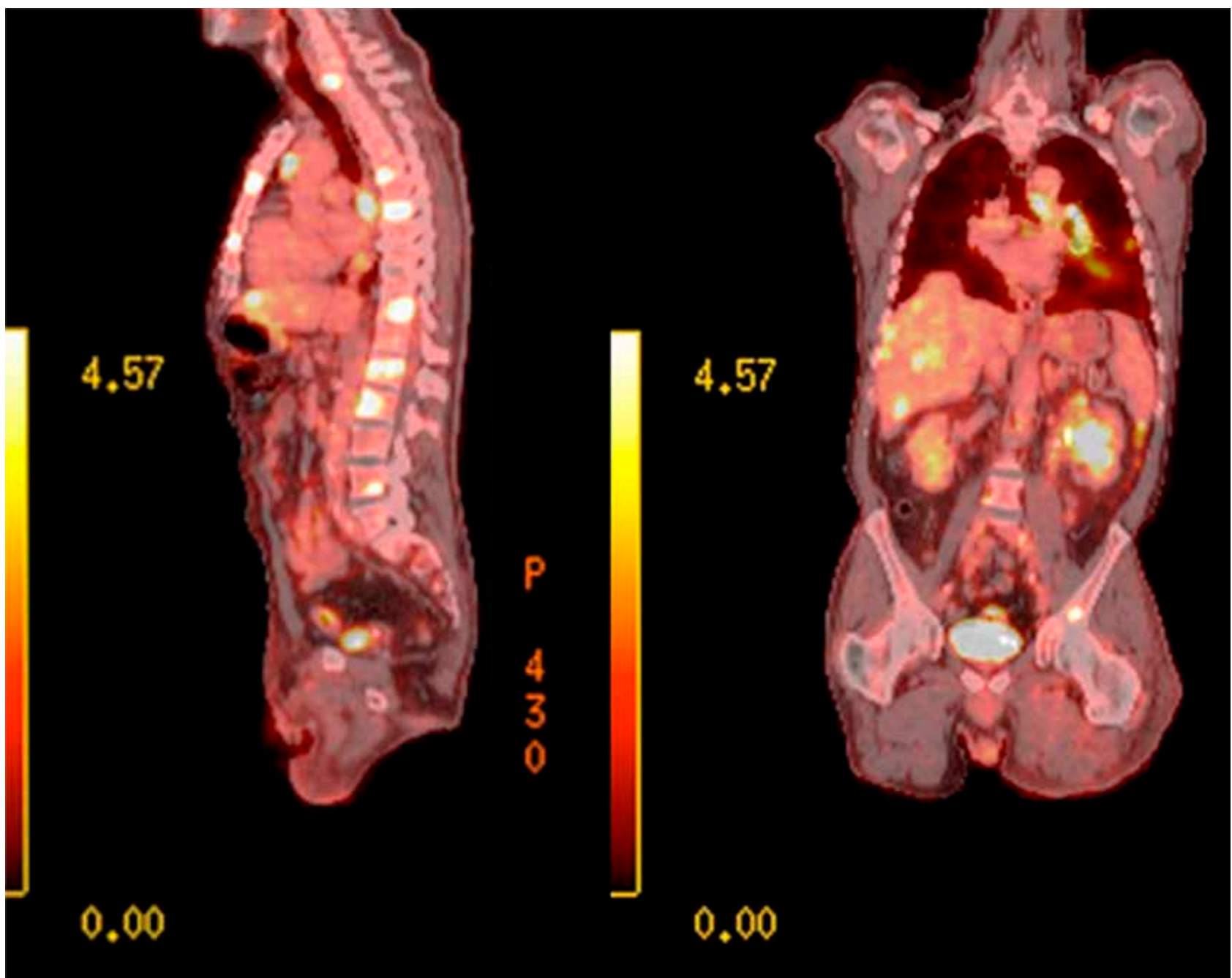

Şekil 1. Yumuşak doku sarkomu nedeni ile takipli 71 yaşındaki hastada, yapılan PET sonucunda frontal planda yaygın karaciğer ve sol böbrek, sagittal planda yaygın vertebral metastazlarının teşhis edilmesi.

yılda \%33 kırık riski ön görülmekte iken, 12 puanda bu risk yılda \%100'dür (Tablo 4). Hastada birden fazla primer kanser tipi mevcut ise, hedef bölgeye ince iğne ya da çekirdek (core) biyopsi uygulaması yapilır.

Kırık beklentisi olan durumlarda; primer tümörün tipi, kemo- ve radyo-sensitivitesi, metastaz yükü, hastanın genel durumu, mevcut ve kullanılabilen ilaçların her biri denklemin içerisinde yer almalıdır. Yine kırık beklentisi durumunda, üst ekstremitenin yük taşımayan kemiklerinde profilaktik ameliyatlar önerilmemektedir. ${ }^{[37]}$ Meme kanserinde profilaktik tespit, yaşam kalitesinin artırılması amacı ile yapılır. Patolojik kırığı olmayan ve uzun kemik metastazı olan hastalarda cerrahi; ağrının ve analjezik kullanımının azaltılması yanı sıra, ambulatuvar kapasitenin ve günlük yaşam aktivitelerinin artırılması amacı ile yapılır.

Primeri bilinmeyen durumlarda, bilinen tümör belirteçleri, hematolojik ve endokrin laboratuvar panelleri ile tarama yapılmalıdır. Ortopedi uzmanının bilmesi gereken, kemik metastazlarının \%70'inde primer kökenin; meme, tiroid, akciğer, karaciğer ve prostat olduğudur. ${ }^{[39]} \mathrm{Bu}$ durumlarda; tüm vücut MR görüntüleme, abdomen, toraks ve pelvis tomografileri, kemik sintigrafisi ve PET-BT, primer tümörün tespit edilmesinde yardımcı yöntemlerdir. Hattâ, bu tanısal araçlara laboratuvar testleri ve gastrointestinal sistem (GiS) endoskopilerinin de eklenmesi ile daha geniş taramalar yapılabilir. 
Tablo 3. Kemik metastazlarının tespitinde tanısal araçlar*

\begin{tabular}{|c|c|c|c|c|}
\hline Metot & Tanım & Duyarlılık/özgüllük & Zamanlama & Kısıtlamalar \\
\hline Düz grafi & İnvaziv değil, ulaşılabilir, ucuz & $\begin{array}{l}\text { Patolojik kırık şüphesinde } \\
\text { duyarlılığı yüksek }\end{array}$ & Erken tanı & $\begin{array}{l}\text { Pelvik ve vertebral } \\
\text { kolon görüntülemeleri }\end{array}$ \\
\hline BT & İnvaziv değil & $\begin{array}{l}\text { Duyarlılık ++ } \\
\text { Özgüllük ++ }\end{array}$ & $\begin{array}{l}\text { Erken tanı } \\
\text { Ameliyat öncesi planlama }\end{array}$ & İmplantlar \\
\hline MR görüntüleme & İnvaziv değil & $\begin{array}{l}\text { Duyarlılık +++ } \\
\text { Özgüllü̈k +++ }\end{array}$ & $\begin{array}{l}\text { Tanısal çalışmayı } \\
\text { tamamlayııı }\end{array}$ & $\begin{array}{l}\text { Ferromanyetik } \\
\text { Implantlar }\end{array}$ \\
\hline Sintigrafi & Radyonüklid İzotop & $\begin{array}{l}\text { Duyarlılık +++ } \\
\text { Özgüllük + }\end{array}$ & $\begin{array}{l}\text { Primer tümör metastaz } \\
\text { taraması }\end{array}$ & $\begin{array}{l}\text { İntravenöz radyoizotop } \\
\text { uygulaması }\end{array}$ \\
\hline FDG-PET & Radyonüklid İzotop & $\begin{array}{l}\text { Duyarlılık +++ } \\
\text { Özgüllük ++ }\end{array}$ & $\begin{array}{l}\text { Primer tümör metastaz } \\
\text { taraması }\end{array}$ & $\begin{array}{l}\text { İntravenöz radyoizotop } \\
\text { uygulaması }\end{array}$ \\
\hline $\begin{array}{l}\text { Tüm vücut } M R \\
\text { görüntüleme }\end{array}$ & İnvaziv değil & $\begin{array}{l}\text { Duyarlılık +++ } \\
\text { Özgüllük +++ }\end{array}$ & $\begin{array}{l}\text { Primer tümör metastaz } \\
\text { taraması }\end{array}$ & $\begin{array}{l}\text { Ferromanyetik } \\
\text { İmplantlar }\end{array}$ \\
\hline $\begin{array}{l}\text { İnce iğne } \\
\text { aspirasyon biyopsi }\end{array}$ & Minimal invaziv & $\begin{array}{l}\text { Duyarlılık \%79,17 } \\
\text { Özgüllük \%72,7 }\end{array}$ & Erken ambulatuvar tanı & Yapı bilgisi eksik \\
\hline $\begin{array}{l}\text { Çekirdek iğne } \\
\text { biyopsi }\end{array}$ & Minimal invaziv & $\begin{array}{l}\text { Duyarlılık \%79,2 } \\
\text { Özgüllü̈k \%81,8 }\end{array}$ & Erken ambulatuvar tanı & $\begin{array}{l}\text { Eksizyonel materyalin } \\
\text { korunan kısmı kadar }\end{array}$ \\
\hline Açık biyopsi & İnvaziv & $\begin{array}{l}\text { Duyarlılık \%100 } \\
\text { Özgüllük \%100 }\end{array}$ & Hastane tanısı & $\begin{array}{l}\text { Eksizyonel materyalin } \\
\text { korunan kısmı kadar }\end{array}$ \\
\hline Sivı biyopsi & Minimal invaziv, genetik test & $\begin{array}{l}\text { Tümöre özgü DNA } \\
\text { Duyarlılık \%100 } \\
\text { Özgüllük \%100 }\end{array}$ & $\begin{array}{l}\text { Erken ambulatuvar tanı, } \\
\text { tekrar edilebilir }\end{array}$ & $\begin{array}{l}\text { Daha fazla klinik } \\
\text { araştırma gerekli }\end{array}$ \\
\hline $\begin{array}{l}\text { BT/MR kılavuzlu } \\
\text { biyopsi }\end{array}$ & Minimal invaziv & $\begin{array}{l}\text { Duyarlılık +++ } \\
\text { Özgüllük +++ }\end{array}$ & $\begin{array}{l}\text { Ambulatuvar ve hastane } \\
\text { tanısı (özel ekip) }\end{array}$ & $\begin{array}{l}\text { Materyalin tam } \\
\text { alınması }\end{array}$ \\
\hline Hiperkalsemi & Minimal invaziv, prognoz ile ilişkili & $\begin{array}{l}\text { Duyarlılık düşük } \\
\text { Özgüllük düşük }\end{array}$ & $\begin{array}{l}\text { Erken tanı ve prognoz } \\
\text { tayini }\end{array}$ & \\
\hline
\end{tabular}

* Łukaszewski ve ark.'nın “Diagnostic methods for detection of bone metastases” derlemesinden alınmıştır. ${ }^{[9]}$

BT, bilgisayarlı tomografi; MR, manyetik rezonans; FDG, florodeoksiglukoz, PET, pozitron emisyon tomografi.

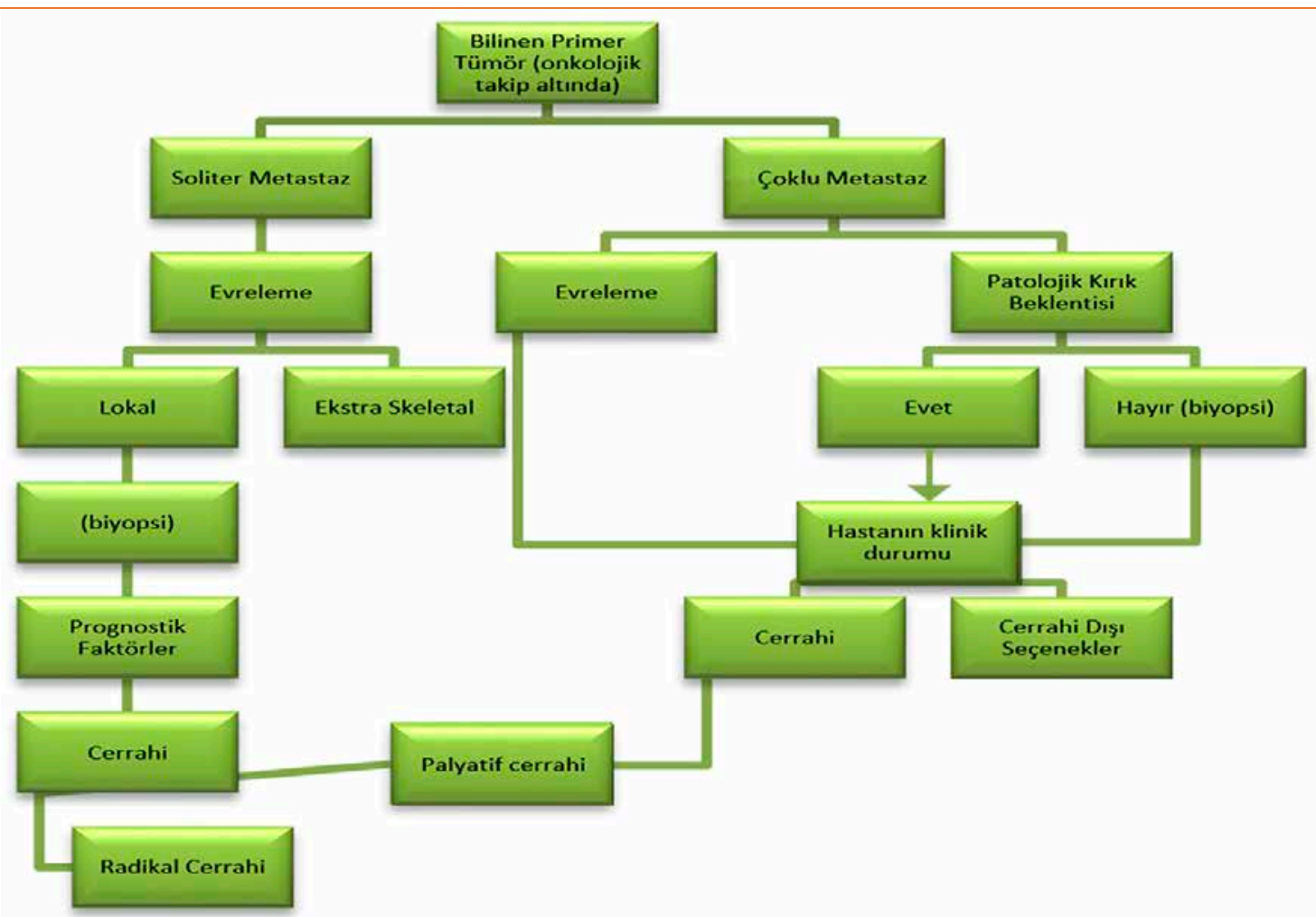

Şekil 2. Bilinen primer tümörü olan olguda beklenen kırık (impending fracture) tanısal algoritması. ${ }^{[38]}$ 
Tablo 4. Kırık riskinin belirlenmesinde kullanılan Mirels'in skorlama sistemi ${ }^{[36]}$

\begin{tabular}{|c|c|c|c|c|c|}
\hline & & & & Toplam skor & 1 yıl içinde kırık (\%) \\
\hline Değişken & 1 & 2 & 3 & $<=6$ & 0 \\
\hline Taraf & Üst ekstremite & Alt ekstremite & Kalça & 7 & 4 \\
\hline Ağrı & $\mathrm{Az}$ & Orta & Fonksiyonel & 8 & 15 \\
\hline Lezyon & Blastik & Litik-blastik & Litik & 9 & 33 \\
\hline \multirow[t]{3}{*}{ Boy } & $<1 / 3$ & $1 / 3-2 / 3$ & $>2 / 3$ & 10 & 72 \\
\hline & & & & 11 & 96 \\
\hline & & & & 12 & 100 \\
\hline
\end{tabular}

Biyopsi, primer tümör kaynağının tespit edilmesinde ve histolojik tanımlamasında yararlıdır; ancak, kemiğin zayıflamasına ve patolojik kırık riskinin artmasına neden olduğu için, primeri bilinmeyen kemik metastazlarında, tanısal algoritmalarda sonlarda yer alır.

Kemik metastazlı hastaların ancak beşte biri, acil travma ünitelerine akut patolojik kırık ile başvurur. Bu durumda, kırığın morfolojisinin, doğal seyrinin ve meydana geliş mekanizmasının tespit edilmeye çalışı ması gerekmektedir. Patolojik kırıkların tedavi ve yönetimleri patolojik olmayan kırıklardan farklıdır. ${ }^{[31]}$ Patolojik kırıklarda tedavi, daha az aceleci ve daha çok temkinli bir yaklaşım gerektirir. Hastanın genel durumunun değerlendirilmesi, prognostik faktörlerin tespit edilmesi ve primer tümörün mevcut durumunun incelenmesi, hedefe yönelik cerrahi tedavinin belirlenmesinde çok etkilidir. Böylece, primer kemik sarkomunda yapılacak intramedüller çivileme gibi telafisi olmayan hatalardan kaçınılması kolaylaşır.

\section{SPINAL METASTAZLARDA TANISAL ALGORITMALAR}

Her ne kadar ilk olarak uzun kemik metastazlarından bahsedilse de, iskelet metastazları en sık vertebral kolonda görülür. ${ }^{[39]}$ Meme kanserinde olguların \%16-37'sinde, oldukça vasküler vertebral kemik iliği ve ekstradural Batson pleksusu, spinal metastazlarda şiddetle suçlanmaktadır. Batson pleksusu aynı zamanda prostat kanserli hastalarda lomber vertebra metastazlarına neden olur. ${ }^{[40,41]}$ Yaşam süreleri arttıkça vertebral metastazlar daha semptomatik hale gelmektedir. ${ }^{[42]}$ Meme kanseri verterbal metastazlarında, en sık torasik bölge semptomatik seyreder. Kanser hastalarında yönetilmesi en zor parametrelerden olan "ağrı" ve vertabral kolonun vücut biyomekaniğinde üstlendiği fonksiyonlar nedeni ile, spinal metastazlar kanser hastalarının yaşam kalitesini etkileyen en önemli unsurdur ve erken teşhis edilmesi gerekir. Osteolitik lezyonlar sonucu meydana gelen medulla spinalis basıları, hem majör nörolojik defisit ile sonuçlanabilir hem de debilize edici (halsizleştirici) ağrılara neden olabilir. Son yıllarda, daha minimal invaziv vertebral girişimler, stereotaktik vücut radyoterapisi gibi, morbidite üzerine etkili yaklaşımlar tedavi planlamalarını değiştirmiştir. Bu yaklaşım, spinal metastazlarda endikasyonların, ortalama sağkalım beklentisi ve genel tıbbi durum değerlendirmesi temeli üzerine inşa edilmesine yol açmaktadır. Spinal metastazlara yaklaşımda kullanılan klasik bir algoritma Şekil 3'te gösterilmiştir. ${ }^{[38]}$

Vertebral metastazı olan hastalar öncelikle; ilerleyici, mekanik olmayan, geceleri daha sık hissedilen ve standart ağrı kesicilere yanıt vermeyen aksiyel ağrı tanımlarlar. Vertebral cismin kollabe olma (çökme) miktarına göre nörolojik bulgular tabloya eklenir. Kök basısı, radiküler ağrıya neden olurken, medulla spinalis basısı miyelopatiye yol açar. Vertebral kompresyon kırıklarında en sık kifoz meydana gelir. Yukarıda anlatıldığı gibi, ilk başvurulması gereken görüntüleme yöntemi düz grafilerdir. Düz grafilerin yardımcı olamadığı durumlarda kemik tarama ve MR kullanılabilir. Spinal metastazların araştırılmasında BT yardımlı transpediküler yaklaşımlı biyopsiler, litik lezyonlarda \%93, sklerotik lezyonlarda \%76 tanısal başarı oranına sahiptir. ${ }^{[43]}$

Kullanılan algoritma ne olursa olsun, vertebral koIon metastazlarında vertebranın biyomekanik stabilitesinin tespit edilmesi şarttır. Vertebral kolon metastazlarında, patolojik kırık ya da buna bağlı gelişen nörolojik defisite bağlı meydana gelen stabilite kaybı, hastanın sağkalımını ve yaşam kalitesini doğrudan etkiler. İnstabiliteye neden olan lezyonların erken tespit edilmesi tedavi seçiminde çok kritiktir; ancak, patolojik kırık gelişmeden stabilitenin değerlendirilmesi, radyolojik ve klinik değerlendirmenin sentezlenmesini gerektirdiği için daha zordur. 


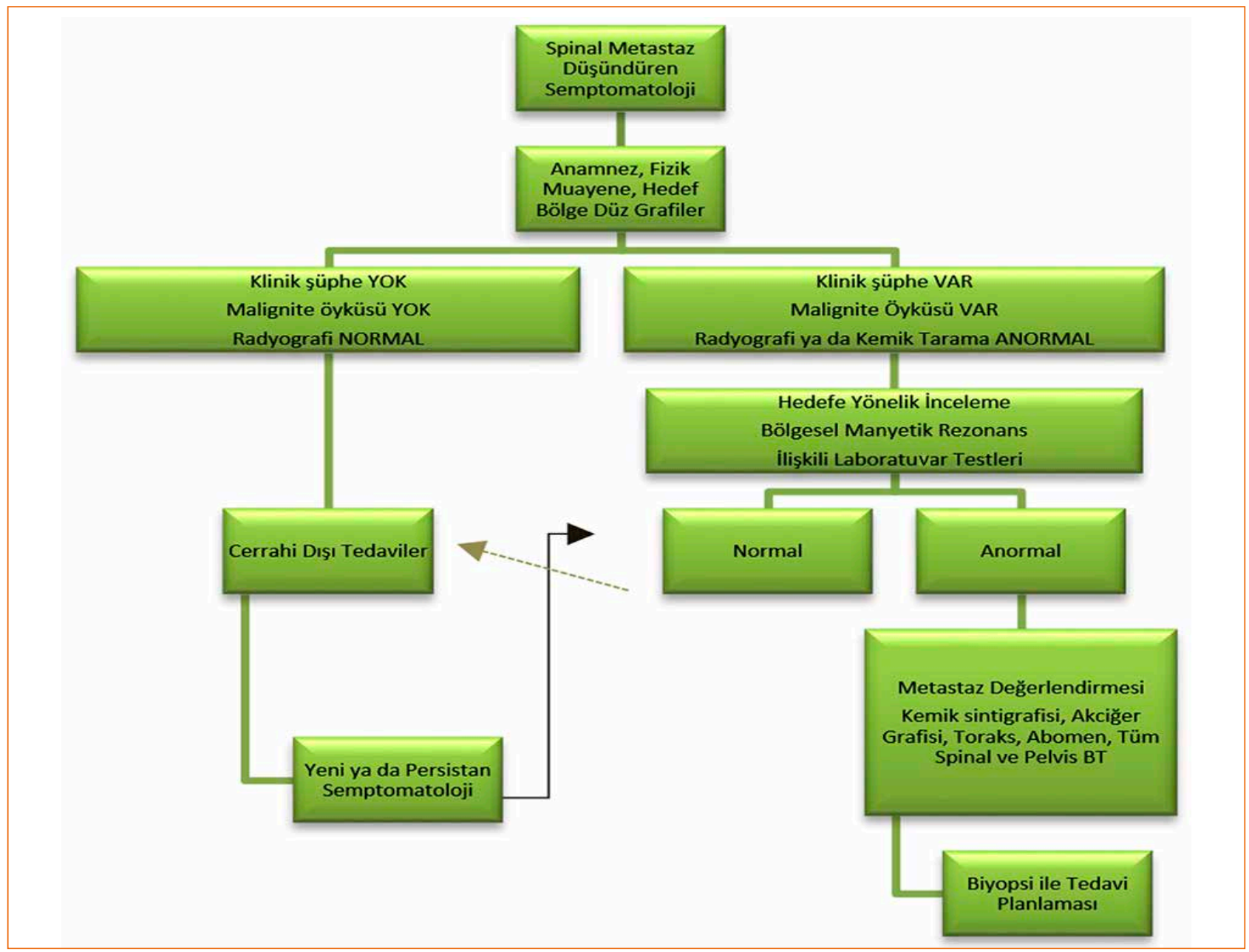

Şekil 3. Spinal metastazlarda kullanılan örnek algoritma. ${ }^{[38]}$

Tümör ile ilişkili spinal instabilite "fizyolojik yüklenme altında nörolojik semptomatoloji, semptomatik/ ilerleyici deformite gelişimi veya hareket ile ilişkili sırt/ bel ağrısı" olarak tanımlanır. ${ }^{[43]}$ Spinal metastazlarda instabilite değerlendirmesinde kullanılan ilk kanıta dayalı algoritma, Spinal Onkoloji Çalışma Grubu (SOST) tarafından 2010 yılında yayımlanmıştır. ${ }^{[44]}$ Spinal instabilite neoplastik skorlaması (SINS) altı parametre kullanılarak hesaplanır (Tablo 5). Sonuçta, 0 ile 18 arasında tespit edilen SINS skoru hastanın tıbbi tedaviyi yürüten hekim tarafindan yönlendirilmesinde yardımcı olur. Daha yüksek skorlar daha fazla instabilite ile ilişkilidir. AO Spine Knowledge Forum on Tumors çalışma grubunun da dâhil olduğu birden fazla çalışmada, bu skorlama sisteminin gözlemciler arasında yüksek oranda güvenilir olduğu tespit edilmiş olup, birçok klinik kılavuzda SINS sistemi yaygın olarak kullanılmaya başlanmıştır. ${ }^{[45]}$ Buna örnek olarak verilebilen NOMS (nörolojik-onkolojik-mekanik-sistemik) ve LMNOP ( $L$, location of disease with respect to the anterior and/or posterior columns of the spine and number of spinal levels involved [contiguous or non-contiguous]; $M$, mechanical instability as graded by SINS; $N$, neurology [symptomatic epidural spinal cord compression]; $O$, oncology [histopathologic diagnosis], particularly with respect to radiosensitivity; and $P$, patient fitness, patient wishes, prognosis [which is mostly dependent on tumor type], and response to prior therapy) adlı iki klinik karar kılavuzu, mekanik instabilite değerlendirmesinde SINS'i kullanmaktadır. Son yıllarda, yüksek SINS skorlarının radyoterapi tekrarı ve spinal yan etkiler ile ilişkili olduğu tespit edilmiştir. Yine de, cerrahi tedavi sonrası sağkalımın SINS skoru ile ilişkisi saptanmasa da mevcut kompresyon kırığı ile birlikte yüksek SINS skorlarının düşük yaşam kalitesi ile ilişkili olduğu tespit edilmiştir. 
Tablo 5. Spinal neoplastik instabilite skorlaması (SINS)

\begin{tabular}{|c|c|}
\hline Lokalizasyon & Skor \\
\hline $\begin{array}{l}\text { - Geçiş bölgeleri (oksiput-C2; C7-T12; } \\
\text { T11-L1; L5-S1) }\end{array}$ & 3 \\
\hline - Tam hareketli bölge (C3-C6; L2-L4) & 2 \\
\hline - Yarı hareketli bölge (T3-T10) & 1 \\
\hline - Tam hareketsiz bölge (S2-S5) & 0 \\
\hline \multicolumn{2}{|l|}{ Ağrı } \\
\hline - Evet & 3 \\
\hline - Zaman zaman mekanik olmayan ağrı & 1 \\
\hline - Ağrısız lezyon & 0 \\
\hline \multicolumn{2}{|l|}{ Lezyon } \\
\hline - Litik & 2 \\
\hline - Karma (Litik ve blastik) & 1 \\
\hline - Blastik & 0 \\
\hline \multicolumn{2}{|l|}{ Radyografik dizilim } \\
\hline - Subluksasyon/translasyon mevcut & 4 \\
\hline - De novo deformite (kifoz/skolyoz) & 2 \\
\hline - Normal dizilim & 0 \\
\hline \multicolumn{2}{|l|}{ Vertebral cisim çökmesi } \\
\hline - >\%50 & 3 \\
\hline - $<\% 50$ & 2 \\
\hline - Çökme yok ancak >\%50 vertebral cisim ilişkili & 1 \\
\hline - Yukardakilerden hiçbiri & 0 \\
\hline \multicolumn{2}{|l|}{ Spinal elementlerin posterolateral dahiliyeti } \\
\hline - Bilateral & 3 \\
\hline - Unilateral & 1 \\
\hline - Hiçbiri & 0 \\
\hline \multicolumn{2}{|l|}{ Toplam skor } \\
\hline - Stabil & $0-6$ \\
\hline - Potansiyel instabil & $7-12 *$ \\
\hline - Instabil & $13-18$ \\
\hline
\end{tabular}

*7 ve üzerindeki skorlarda ortopedik omurga cerrahisi konsültasyonu önerilmektedir.

\section{KEMIK METABOLIZMASI BIYOBELIRTEÇLERI VE OSTEOTROPIK KANSERLERIN GELECEĞi}

İskelet metastazları ile ilgili araştırmalar, önceleri tedavi yöntemleri ve yaklaşım modellemelerinin belirlenmesi üzerine yoğunlaşırken, son yirmi yıl içerisinde moleküler ve genetik düzeylere evrilmiştir. Günümüzde en önemli hedeflerden biri "yüksek riskli" hastaların belirlenmesi ve özellikle meme kanserinde adjuvan bisfosfonat terapisi ile osteotropinin modifiye edilmeye çalışılmasıdır. ${ }^{[46]}$ Özellikle, araştırmalar meme, prostat ve akciğer kanserleri üzerine yoğunlaşmakta ve kemik metastazlarının önceden tahmin edilebilmesi amacı ile şimdiden birçok "Kemik Metastazı Biyobelirteci" ve "Kemik Turnover Biyobelirteci” (BTM) tespit edilmiştir. BTM'ler kemik rezorpsiyonu ve kemik formasyonunu tespit etme yeteneğine göre iki ayrı tipte sınıflandırılmaktadır (Tablo 6). Bazı çalışmalar, BTM seviyeleri ile kemik metastazların arasındaki doğrusal ilişkileri kanıtlamakta, ancak halen özgüllük, duyarlılık ve tanısal etkinlik çalışmalarının eksiklikleri nedeni ile rutin protokollerde bu yer almamaktadır. ${ }^{[47]}$ Kemik metastazları biyobelirteçleri üzerinde, BTM'lerden daha farklı olarak, gen, m-RNA ya da protezin sentezi işaretleyicileri olarak çeşitli neoplazilerde tespit amacı ile çalışılmaktadır. Buna Kang'ın kendi imzası ile tanımladığı, IL-11, FGF ve CXCCR-4 kompleksinin meme kanserindeki kullanımı örnek olarak verilebilir. ${ }^{[48]}$ Bazı yazarlar tarafından bu çalışmalara "Sıvı Biyopsi" de denmektedir. ${ }^{[9]}$

İskelet metastazlarının öngörülmesinde, halen yakın zamanda araştırılmakta olan moleküller ya da oluşturulan skorlama sistemleri kesin bir yarar sağlamamaktadır. Dolayısı ile, cerrahi kararı; kişisel faktörlerin göz önünde bulundurulması, skorlamalar ve multidisipliner bir bakış açısı ile verilmelidir. Ancak, moleküler ve genetik düzeyde yapılan çalışmalar, hem öngörü hem de prognostik tahminlerin daha güçlü yapılması konusunda umut vericidir.

Tablo 6. Serum ya da idrarda tespit edilebilen kemik turnover biyobelirteçleri

\begin{tabular}{ll}
\hline Formasyon tipi & Rezorpsiyon tipi \\
\hline - Kemik alkalen fosfataz (BALP) & - Tip 1 kollajenin C-telopeptidi (CTX) \\
- Prokollajen Tip 1, N-terminal peptid (PINP) & - Tip 1 kollajenin N-telopeptidi (NTX) \\
- Prokollajen Tip 1, C-terminal peptid (PICP) & - Piridinolin (PYD) \\
& - Tartar dirençli asit fosfataz (TRACP) \\
& - Çaprazlanmış karboksi-terminal telopeptit (ICTP)
\end{tabular}




\section{KAYNAKLAR}

1. Chambers A, Naumov G, Varghese $H$, Nadkarni KV, MacDonald IC, Groom AC. Critical steps in hematogenous metastasis: an overview. Surg Oncol Clin $N$ Am 2001;10(2):243-55. Crossref

2. Luzzi KJ, MacDonald IC, Schmidt EE, Kerkvliet N, Morris VL, Chambers AF, Groom AC. Multistep nature of metastatic inefficiency: dormancy of solitary cells after successful extravasation and limited survival of early micrometastases. Am J Pathol 1998;153(3):865-73. Crossref

3. Coleman R. Metastatic bone disease: clinical features, pathophysiology and treatment strategies. Cancer Treat Rev 2001;27(3):165-76. Crossref

4. Michael HH, Tsai Y, Hoffe SE. Overview of diagnosis and management of metastatic disease to bone. Cancer Control 2012;19(2):84-91. Crossref

5. Selvaggi G, Scagliotti G. Management of bone metastases in cancer: a review. Clin Rev Oncol Hematol 2005;56(3):36578. Crossref

6. Healey JH, Turnbull AD, Miedema B and Lane JM. Acrometastases. A study of twenty-nine patients with osseous involvement of the hands and feet. J Bone Joint Surg Am 1986;68(5):743-6. Crossref

7. Libson E, Bloom RA, Husband JE, Stoker DJ. Metastatic tumours of bones of the hand and foot. A comparative review and report of 43 additional cases. Skeletal Radiol 1987;16(5):387-92. Crossref

8. Lumachi F, Brunello A, Roma A, Basso U. Medical treatment of malignancy-associated hypercalcemia. Curr Med Chem 2008;15(4):415-21. Crossref

9. Łukaszewski B, Nazar J, Goch M, Łukaszewska M, Stepinski A, Jurczyk MU. Diagnostic methods for detection of bone metastases. Contemp Oncol 2017;21(2):98-103. Crossref

10. Rosenthal DI. Radiologic diagnosis of bone metastases. Cancer 1997;80(8 Suppl):1595-607. Crossref

11. Jehn CF, Diel IJ, Overkamp F, Kurth A, Schaefer R, Miller $K$, Lueftner D. Management of metastatic bone disease algorithms for diagnostics and treatment. Anticancer Res 2016;36(6):2631-7.

12. Heindel W, Gübitz R, Vieth V, Weckesser M, Schober O, Schäfers M. The Diagnostic Imaging of Bone Metastases. Dtsch Ärztebl Int 2014;111(44):741-7. Crossref

13. Evans A, Robertson J. Magnetic resonance imaging versus radionuclide scintigraphy for screening in bone metastases. Clin Radiol 2000;55(8):653. Crossref

14. Broski SM, Young JR, Kendi AT, Subramaniam RM. Skeletal Metastasis Evaluation: Value and Impact of PET/Computed Tomography on Diagnosis, Management and Prognosis. PET Clin 2019;14(1):103-20. Crossref

15. Algra $\mathrm{P}$, Bloem J, Tissing $\mathrm{H}$, Falke TH, Arndt JW, Verboom LJ. Detection of vertebral metastases: comparison between MRI and bone scintigraphy. Radiographics 1991;11(2):219-32. Crossref

16. Shibata $H$, Kato $S$, Sekine I, Abe $K$, Araki N, Iguchi $H$, Izumi T, Inaba Y, Osaka I, Kato S, Kawai A, Kinuya S, Kodaira M, Kobayashi E, Kobayashi T, Sato J, Shinohara N, Takahashi S, Takamatsu Y, Takayama K, Takayama K, Tateishi U, Nagakura $\mathrm{H}$, Hosaka M, Morioka $\mathrm{H}$, Moriya $\mathrm{T}$, Yuasa $\mathrm{T}$, Yurikusa $\mathrm{T}$, Yomiya K, Yoshida M. Diagnosis and treatment of bone metastasis: comprehensive guideline of the Japanese Society of Medical Oncology, Japanese Orthopedic Association, Japanese Urological Association, and Japanese Society for Radiation Oncology. ESMO Open 2016;1:e000037. Crossref
17. Marom E, McAdams H, Erasmus J, Goodman PC, Culhane DK, Coleman RE, Herndon JE, Patz EF. Staging nonsmall cell lung cancer with whole-body PET. Radiology 1999;212(3):803-9. Crossref

18. Yang S, Liang J, Lin F, Kao C, Lin C, Lee C. Comparing whole-body 18FDG PET and technetium-99m methylene diphosphonate bone scan to detect bone metastases in patients with breast cancer. J Cancer Res Clin Oncol 2002;128(6):325-8. Crossref

19. Schirrmeister $H$, Guhlmann A, Elsner K, Kotzerke J, Glatting G, Rentschler M, Neumaier B, Träger H, Nüssle K, Reske SN. Sensitivity in detecting osseous lesions depends on anatomic localization: planar bone scintigraphy versus $18 \mathrm{~F} \mathrm{PET}$. J Nucl Med 1999;40(10):1623-9. Erişim: http://jnm.snmjournals. org/content/40/10/1623.long

20. Eisenhauer EA, Therasse $P$, Bogaerts J, Schwartz LH, Sargent D, Ford R, Dancey J, Arbuck S, Gwyther S, Mooney M, Rubinstein L, Shankar L, Dodd L, Kaplan R, Lacombe $D$, Verweij J. New response evaluation criteria in solid tumours: revised RECIST guideline (version 1.1). Eur J Cancer 2009;45(2):228-47. Crossref

21. Shen CT, Qiu ZL, Han TT, Luo QY. Performance of 18 Ffluoride PET or PET/CT for the detection of bone metastases: a metaanalysis. Clin Nucl Med 2015;40(2):103-10. Crossref

22. lagaru A, Mittra E, Dick DW, Gambhir SS. Prospective evaluation of (99m) Tc MDP scintigraphy, (18)F NaF PET/CT, and (18)F FDG PET/CT for detection of skeletal metastases. Mol Imaging Biol 2012;14(2):252-9. Crossref

23. Sampath SC, Sampath SC, Mosci C, Lutz AM, Willmann JK, Mittra ES, Gambhir SS, lagaru A. Detection of osseous metastasis by $18 \mathrm{~F}-\mathrm{NaF} / 18 \mathrm{~F}-\mathrm{FDG} \mathrm{PET} / \mathrm{CT}$ versus $\mathrm{CT}$ alone. Clin Nucl Med 2015;40(3):e173-7. Crossref

24. Hetzel M, Arslandemir $C$, König HH, Buck AK, K Nüssle, Glatting G, Gabelmann A, Hetzel J, Hombach V, Schirrmeister H. F-18 NaF PET for detection of bone metastases in lung cancer: accuracy, cost-effectiveness, and impact on patient management. J Bone Miner Res 2003;18(12):2206-14. Crossref

25. Hahn $S$, Heusner $T$, Kummel $S$, Köninger A, Nagarajah J, Müller S, Boy C, Forsting M, Bockisch A, Antoch G, Stahl A. Comparison of FDG-PET/CT and bone scintigraphy for detection of bone metastases in breast cancer. Acta Radiol 2011;52(9):1009-14. Crossref

26. Morris PG, Lynch C, Feeney JN, Patil S, Howard J, Larson SM, Dickler M, Hudis CA, Jochelson M, McArthur HL. Integrated positron emission tomography/computed tomography may render bone scintigraphy unnecessary to investigate suspected metastatic breast cancer. J Clin Oncol 2010;28(19):3154-9. Crossref

27. Wu Y, Li P, Zhang $H$, Shi $Y$, Wu H, Zhang J, Qian Y, Li C, Yang J. Diagnostic value of fluorine 18 fluorodeoxyglucose positron emission tomography/ computed tomography for the detection of metastases in non-small-cell lung cancer patients. Int J Cancer 2013;132(2):E37-47. Crossref

28. Nanni C, Schiavina R, Brunocilla E, Boschi S, Borghesi M, Zanoni L, Pettinato C, Martorana G, Fanti S. 18F-Fluciclovine $\mathrm{PET} / \mathrm{CT}$ for the detection of prostate cancer relapse: a comparison to 11C-Choline PET/CT. Clin Nucl Med 2015;40(8):e386-91. Crossref

29. Ceci F, Castellucci P, Graziani T, Schiavina R, Chondrogiannis S, Bonfiglioli R, Costa S, Virgolini IJ, Rubello D, Fanti S, Colletti PM. 11C-choline PET/CT identifies osteoblastic and osteolytic lesions in patients with metastatic prostate cancer. Clin Nucl Med 2015;40(5):e265-70. Crossref 
30. Fuccio C, Castellucci P, Schiavina R, Guidalotti PL, Gavaruzzi G, Montini GC, Nanni C, Marzola MC, Rubello D, Fanti S. Role of 11C-choline PET/CT in the re-staging of prostate cancer patients with biochemical relapse and negative results at bone scintigraphy. Eur J Radiol 2012;81(8):e893-6. Crossref

31. Willeumier JJ, van der Linden YM, van de Sande MAJ, Dijkstra PDS. Treatment of pathological fractures of the long bones. EFORT Open Rev 2017;1(5):136-45. Crossref

32. Biermann JS, Holt GE, Lewis VO, Schwartz HS, Yaszemski MJ. Metastatic bone disease: diagnosis, evaluation, and treatment. J Bone Joint Surg Am 2009;91(6):1518-30.

33. Bickels J, Dadia S, Lidar Z. Surgical management of metastatic bone disease. J Bone Joint Surg Am 2009;91(6):1503-16. Crossref

34. Ashford RU, Pendlebury S, Stalley PD. Management of metastatic disease of the appendicular skeleton. Curr Orthop 2006;20(4):299-315. Crossref

35. Ruggieri P, Mavrogenis AF, Casadei R, Errani C, Angelini A, Calabrò T, Pala E, Mercuri M. Protocol of surgical treatment of long bone pathological fractures. Injury 2010;41(11):11617. Crossref

36. Mirels $\mathrm{H}$. Metastatic disease in long bones. A proposed scoring system for diagnosing impending pathologic fractures. Clin Orthop Relat Res 1989;(249):256-64. Crossref

37. Laitinen M, Ratasvuori M, Pakarinen TK. The multi-modal approach to metastatic diseases. In: Bentley G, editor. European Intructional Lectures, Vol 12. Berlin, Heidelberg: Springer; 2012. pp.35-44.

38. Salduz A, Eralp L. The Local Management of Bone Metastases. In: Aydiner A, İgci A Soran A, editors. Breast Disease, Management and Therapies, Vol 2. Switzerland: Springer Nature Switzerland AG; 2019. pp. 619-33. Crossref

39. Ratasvuori M, Wedin R, Keller J, Nottrott M, Zaikova O, Bergh $P$, Kalen A, Nilsson J, Jonsson H, Laitinen M. Insight opinion to surgically treated metastatic bone disease: Scandinavian Sarcoma Group Skeletal Metastasis Registry report of 1195 operated skeletal metastasis. Surg Oncol 2013;22(2):132-8. Crossref

40. White AP, Kwon BK, Lindskog DM, Friedlaender GE, Grauer JN. Metastatic disease of the spine. J Am Acad Orthop Surg 2006;14(11):587-98. Crossref

41. Batson OV. The function of the vertebral veins and their role in the spread of metastases. Ann Surg 1940;112(1):138-49. Crossref
42. Smith BD, Smith GL, Hurria A, Hortobagyi GN, Buchholz TA. Future of cancer incidence in the United States: burdens upon an aging, changing nation. J Clin Oncol 2009;27(17):275865. Crossref

43. Lis E, Bilsky MH, Pisinski L, Boland P, Healey JH, O'malley B, Krol G. Percutaneous CT-guided biopsy of osseous lesion of the spine in patients with known or suspected malignancy. AJNR Am J Neuroradiol 2004;25(9):1583-88. Erişim: http:// www.ajnr.org/content/25/9/1583.long

44. Fisher CG, DiPaola CP, Ryken TC, Bilsky MH, Shaffrey $\mathrm{Cl}$, Berven SH, Harrop JS, Fehlings MG, Boriani S, Chou D, Schmidt MH, Polly DW, Biagini R, Burch S, Dekutoski MB, Ganju A, Gerszten PC, Gokaslan ZL, Groff MW, Liebsch NJ, Mendel E, Okuno SH, Patel S, Rhines LD, Rose PS, Sciubba DM, Sundaresan N, Tomita K, Varga PP, Vialle LR, Vrionis FD, Yamada Y, Fourney DR. A novel classification system for spinal instability in neoplastic disease: an evidence-based approach and expert consensus from the Spine Oncology Study Group. Spine (Phila Pa 1976) 2010;35(22):E1221-9. Crossref

45. Fourney DR, Frangou EM, Ryken TC, Dipaola CP, Shaffrey $\mathrm{CI}$, Berven SH, Bilsky MH, Harrop JS, Fehlings MG, Boriani S, Chou D, Schmidt MH, Polly DW, Biagini R, Burch S, Dekutoski MB, Ganju A, Gerszten PC, Gokaslan ZL, Groff MW, Liebsch NJ, Mendel E, Okuno SH, Patel S, Rhines LD, Rose PS, Sciubba DM, Sundaresan N, Tomita K, Varga PP, Vialle LR, Vrionis FD, Yamada Y, Fisher CG. Spinal instability neoplastic score: an analysis of reliability and validity from the spine oncology study group. J Clin Oncol 2011;29(22):3072-7. Crossref

46. Coleman R, Cameron D, Dodwell D, Bell R, Wilson C, Rathbone E, Keane M, Gil M, Burkinshaw R, Grieve R, BarrettLee P, Ritchie D, Liversedge V, Hinsley S, Marshall H. Adjuvant zoledronic acid in patients with early BC. Final efficacy analysis of the AZURE (BIG 01/04) randomised open-label phase 3 trial. Lancet Oncol 2014;15(9):997-1006. Crossref

47. D'Oronzo S, Brown J, Coleman R. The value of biomarkers in bone metastasis. Eur J Cancer Care 2017;26(6):e12725. Crossref

48. Kang Y, Siegel PM, Shu W, Drobnjak M, Kakonen SM, Cordòn-Cardo C, Guise TA, Massague J. A multigenic program mediating breast cancer metastasis to bone. Cancer Cell 2003;3(6):537-49. Crossref 